\title{
Ein Adliger als Revolutionär. Alexander Herzens frühe Prosa im literarischen und kulturellen Kontext der „natural'naja škola“"
}

\author{
Peters, Jochen-Ulrich
}

\begin{abstract}
The article shows, how Alexander Herzen, following Heine's "Reisebilder", develops a new poetic and journalistic style of writing, which specifically corresponds to the literary and cultural norms of the "Natural School". At the same time, his early prose works demonstrate the difficulties which a young noble and radical intellectual had in reconciling his revolutionary mind-set with his convictions about the individual's right to liberty and material independence. Herzen defended these convictions above all, not only against the Czarist autocracy and Western Europe's civil society, but also against the peasants' communal organization in a future socialist Russia
\end{abstract}

DOI: https://doi.org/10.1524/slaw.2012.0035

Posted at the Zurich Open Repository and Archive, University of Zurich

ZORA URL: https://doi.org/10.5167/uzh-155433

Journal Article

Published Version

Originally published at:

Peters, Jochen-Ulrich (2012). Ein Adliger als Revolutionär. Alexander Herzens frühe Prosa im literarischen und kulturellen Kontext der „natural'naja škola“. Zeitschrift für Slawistik, 57(4):462-481.

DOI: https://doi.org/10.1524/slaw.2012.0035 
Jochen-Ulrich Peters

\title{
Ein Adliger als Revolutionär. Alexander Herzens frühe Prosa im literarischen und kulturellen Kontext der ,natural'naja škola“
}

\author{
Summary
}

The article shows, how Alexander Herzen, following Heine's „Reisebilder”, develops a new poetic and journalistic style of writing, which specifically corresponds to the literary and cultural norms of the "Natural School". At the same time, his early prose works demonstrate the difficulties which a young noble and radical intellectual had in reconciling his revolutionary mind-set with his convictions about the individual's right to liberty and material independence. Herzen defended these convictions above all, not only against the Czarist autocracy and Western Europe's civil society, but also against the peasants' communal organization in a future socialist Russia.

Keywords: Literature and politics; The beginnings of Russian realism; Heine in Russian literature

\section{$I$.}

In seiner umfangreichen Monographie „A Parting of Ways“ hat Nicholas V. Riasanovsky bereits 1976 zeigen können, wie sich die russische Intelligencija seit den 1830er Jahren in zunehmendem Maße von den Machtinteressen und Legitimationsansprüchen der zaristischen Autokratie entfernt, um diesen ihre eigenen, sehr unterschiedlich motivierten politischen Überzeugungen und ideologischen Entwürfe entgegenzusetzen. Dabei hat die intensive Beschäftigung mit der Philosophie des deutschen Idealismus und der Gesellschaftstheorie der französischen Sozialisten sowie die nachhaltige Rezeption der europäischen Romantik erheblich dazu beigetragen, dass die noch im 18. und frühen 19. Jahrhundert so weit verbreitete Orientierung an den Idealen der französischen und russischen Aufklärung zunehmend an Bedeutung verliert. An deren Stelle tritt die seit der Französischen Revolution propagierte, in Russland vor allem von den Dekabristen verbreitete Hoffnung auf die Freiheit und die weltverändernde Kraft des Individuums oder einzelner politischer Gruppierungen, die mit der restriktiven Herrschaft und autokratischen Gesellschaftsordnung unter dem Zaren Nikolaj I. nicht zu vereinbaren war. Diese kontinuierliche Entfremdung der russischen, zunächst noch weitgehend vom Adel dominierten, Intelligencija von der zaristischen Regierung und der den Staat und die Gesellschaft beherrschenden und kontrollierenden Bürokratie hat Riasanovsky am Ende seiner detaillierten kultur- und ideologiegeschichtlichen Darstellung in folgender Weise zusammengefasst: "What was collapsing was not only the concept of enlightened despotism, or of autocracy, but an entire intellectual order."

Dieses Spannungsverhältnis zwischen dem autokratischen Staat und der russischen Intelligencija hat Alexander Herzen in seinen Memoiren „Byloe i dumy“ aus der Retroperspektive in allen Einzelheiten beschrieben und politisch zu begründen versucht. Allerdings wer-

1 N.V. RiaZANOvSKy, A Parting of Ways. Government and the educated Public in Russia 1801-1855, Oxford 1976, S. 290. 
den in diesen, erst in den 1850er und 1860er Jahren im Londoner Exil verfassten autobiographischen Schilderungen die erheblichen Brüche und Schwierigkeiten nicht immer deutlich genug benannt, die die Entwicklung eines aus einer außerordentlich angesehenen und wohlhabenden Adelsfamilie stammenden Intellektuellen zu einem revolutionären Denker und Schriftsteller geprägt und erheblich erschwert haben. Denn Herzen war zwangsläufig daran interessiert, vor allem seine uneheliche Geburt und seine unglückliche, von der eigenen Familie weitgehend isolierte Kindheit und Jugend zu betonen, um demgegenüber seine frühe Verbundenheit mit dem russischen Volk, insbesondere den Bediensteten in seinem Elternhaus und den leibeigenen Bauern auf dem Landgut seines Vaters, herauszustellen. Demgegenüber lässt seine frühe Prosa die innere Zerrissenheit und die aus ihr resultierenden politischen und weltanschaulichen Unsicherheiten und Inkonsequenzen sehr viel deutlicher erkennen, die sich aus der aristokratischen Bildung und Erziehung durch das Elternhaus und das philosophische und naturwissenschaftliche Studium an der Universität in Moskau ergaben. Zwar sind alle diese frühen Texte in ihrem Wahrheitsgehalt und ihrer Authentizität dadurch begrenzt, dass Herzen wegen der Rücksicht auf die Zensur und der nur zu begründeten Furcht vor einer erneuten Verhaftung und Verbannung seine Kritik und Empörung gegenüber dem despotischen Herrschaftssystem Nikolajs I. längst nicht so offen und dezidiert zum Ausdruck bringen konnte wie in seinen später in Westeuropa entstandenen und veröffentlichten Memoiren und publizistischen Schriften. Jedoch zeigen seine ebenfalls bereits stark autobiographisch geprägten frühen literarischen Versuche umso eindrucksvoller, wie sich ein junger Adliger zu einem revolutionären Schriftsteller und Publizisten zu entwickeln versucht, der trotz seiner Hoffnungen auf eine radikale Veränderung der Gesellschaft seine eigene persönliche Freiheit und materielle Unabhängigkeit sowie die Freiheit der Kunst und der Literatur gegenüber allen sozialistischen Zielen und Überzeugungen hartnäckig verteidigt. Sein einziger abgeschlossener Roman „Kto vinovat?" lässt ebenso wie die ihm vorausgehenden „Zapiski molodogo čeloveka“ erkennen, wie außerordentlich schwierig es war, die adlige Erziehung und Bildung und die mit ihr verbundenen aristokratischen Lebens- und Bewusstseinsformen zu überschreiten, auch wenn Herzen durch die frühen Verbannungen nach Vjatka, Vladimir und später Novgorod die Brutalität und Willkür der zaristischen Bürokratie und die extrem schwierigen Lebensbedingungen der verarmten und ungebildeten Bevölkerung auf dem Lande und in der russischen Provinz schon früh kennenlernte. Insofern zeigen die frühen literarischen Texte noch sehr viel deutlicher als die späteren Memoiren, dass E. H. Carr in seinem historischdokumentarischen Familienroman Bakunin, Herzens lebenslänglichen Freund Ogarev und vor allem Herzen selbst sehr zu Recht als „Romantiker der Revolution“ bezeichnet hat. ${ }^{2}$ Denn die stark ausgeprägte Skepsis gegenüber einer umfassenden politischen und ökonomischen Veränderung der bestehenden russischen Gesellschaft überformt und relativiert immer wieder die oft geradezu enthusiastischen Hoffnungen auf eine umfassende Erneuerung der Welt im Sinne der utopischen Ideale und Entwürfe von Schelling, Saint-Simon oder später Proudhon. ${ }^{3}$

2 E.H. CARR, Romantiker der Revolution. Ein russischer Familienroman aus dem 19. Jahrhundert. Aus dem Englischen von R. Kaiser, Ffm. 2004.

3 Eine eingehende Darstellung der persönlichen und intellektuellen Entwicklung bietet die vorzüglich dokumentierte Monographie von MARTin MaLiA, Alexander Herzen and the Birth of Russian 
Herzens frühe Prosa ist aber auch im Hinblick auf die tiefgreifenden Veränderungen der russischen Literatur in den 1830er und frühen 1840er Jahren außerordentlich aufschlussreich. Denn früher und konsequenter als der junge Turgenev, Dostoevskij oder Gončarov entwickelt Herzen eine neue Schreibweise, die er geradezu programmatisch der Dichtung und den sie begründenden ästhetischen Theorien von Goethe, Schiller und den russischen und westeuropäischen Romantikern gegenüberstellt. Dabei verweist er bereits in der Einleitung zu den „Zapiski molodogo čeloveka“ auf Heinrich Heine, der sich in seinen „Reisebildern“ und seinen kritischen Abhandlungen über die „Romantische Schule“ wenige Jahre früher ebenso dezidiert gegen die nicht länger zeitgemäße Kunst und Literatur der sog. „Kunstperiode“ wandte. Hatte doch schon Heine zu erklären und zu begründen versucht, warum die zeitgenössische und zeitgemäße Kunst und Literatur nicht länger eine „unabhängige zweite Welt“ entwerfen dürfe, um sich nicht „von den Ansprüchen jener ersten Welt, welcher doch der Vorrang gebührt, abzuwenden.“4

Zwar wird auch von Herzen deshalb nicht vorbehaltlos eine ausschließlich politisch orientierte und engagierte Literatur verlangt und verteidigt, da auch von ihm, wie von Heine, die subjektive ästhetische Erfahrung des Schriftstellers keineswegs ausgeblendet oder auch nur gering veranschlagt wird. Aber auch Herzens frühe Prosa lässt einen ähnlichen „Funktionsübergang von Dichtung und Publizistik“ erkennen, wie ihn W. Preisendanz im Hinblick auf Heine in folgender Weise beschrieben hat:

Anstatt einer sich selbst tragenden und haltenden ,dargestellten Wirklichkeit', einer abgeschlossenen Welt des ästhetischen Scheins, haben wir ein Gewebe aufgedrungener oder intendierter Wirklichkeitsbezüge vor uns. Und dieses Präsentieren von Wirklichkeitsbezügen wird noch dadurch facettiert, dass eine Sequenz der mannigfaltigsten subjektiven Modi (...) zum Ausdruck kommt, in denen sich der jeweilige Wirklichkeitsbezug realisiert: Beobachtung, Analyse, Imagination, Reminiszenz, Traum, Stimmung, Affekt, Meditation, Reflexion, Dialog, Lektüre sind nur einige solcher Einfallstore, Gleise, Kanäle für den Kommerz zwischen Bewusstsein und Realität. ${ }^{5}$

Sobald man mit diesen, auf Heines „Reisebilder“ bezogenen Kategorien Herzens frühe „Zapiski molodogo čeloveka“ betrachtet und zu analysieren versucht, ergeben sich erstaunlich direkte Parallelen und Übereinstimmungen. Herzen zitiert aus der „Reise von München nach Genua“, dem dritten Teil der „Reisebilder“, die folgende Feststellung: „Jeder einzelne Mensch ist schon eine Welt, die mit ihm geboren wird und mit ihm stirbt, unter jedem Grabstein liegt eine Weltgeschichte. “6

Socialism. 1812-1855, Cambridge (Mass.), 1961 sowie die konzise Studie von E. Acton, Alexander Herzen and the Role of the Intellectual Revolutionary, Cambridge u.a. 1979.

4 H. HeINE, Sämtliche Schriften, Bd. 5, München 1976, S. 393. Eine eingehende Darstellung dieser Epochenschwelle innerhalb der russischen Literatur- und Kulturgeschichte bietet der Sammelband „Das ,Ende der Kunstperiode’. Kulturelle Veränderungen des ,literarischen Feldes' in Russland zwischen 1825 und 1842, hrsg. von J.-U. PETERS und U. SCHMID, Bern u. a. 2007.

5 W. Preisendanz, Der Funktionsübergang von Dichtung und Publizistik, in: DERS., Heinrich Heine. Werkstrukturen und Epochenbezüge, München 1983, S. 31.

$6 \quad$ H. HeINE, Sämtliche Schriften, Bd.3, S. 378. Vgl. die wörtliche Übersetzung dieser Passage innerhalb der „Zapiski molodogo čeloveka“ in: A.I. GERCEN, Sobranie sočinenij v tridcati tomach, Bd. 1, M. 
Damit wird von Heine und mit ihm auch von Herzen die eminente Bedeutung und unzerstörbare Identität des Individuums in den Mittelpunkt gerückt, um von ihm aus die Geschichte der Welt und die Entwicklung der Menschheit zu begreifen und zu beschreiben. Anders als in den späteren Memoiren und publizistischen Schriften ist es noch nicht der von sozialistischen Ideen und Zukunftserwartungen bestimmte Progress der Menschheit, sondern das diesen gleichsam anstoßende und beeinflussende Subjekt, auf das es Herzen in diesem Zusammenhang vor allem ankommt. Noch aufschlussreicher für die Entwicklung des jungen Herzen ist indessen Heines, sich an diese Feststellung anschließendes Bekenntnis, das Herzen vermutlich mit Rücksicht auf die Zensurbehörde nicht mitzitiert: „Wir aber leben und wollen weiter kämpfen im heiligen Befreiungskriege der Menschheit." ${ }^{77}$ Denn es umschreibt sehr genau das idealistische Pathos und die eher abstrakte Hoffnung auf eine umfassende Veränderung der Welt, von denen auch Herzens ,Zapiski molodogo čeloveka" und seine übrigen frühen literarischen und publizistischen Texte sowie seine Tagebücher so stark geprägt sind. Wie für Heine ist deshalb auch für Herzen nur noch eine Schreibart zeitgemäß und legitim, in der die publizistische Dimension und Wirkungsintention den literarischen Text gleichsam überformen und in bestimmter Weise ausrichten sollte. Dabei sollte allerdings die subjektive Erfahrung und Empfindung des Schriftstellers in keiner Weise eingeschränkt oder auch nur reduziert werden, die sich auch in Herzens Texten gleichzeitig in komisch-ironischen Schilderungen und diese immer wieder unterbrechenden pathetischen Exklamationen manifestiert. Diese bewusste Hervorhebung der Subjektivität des Schreibens und Reflektierens hat aber die Konsequenz, dass bei Herzen, wie bereits bei Heine in den „Reisebildern“, eine ,welthaft in sich zusammenhängende phänomenale Wirklichkeit" nicht länger zur Darstellung kommt. Stattdessen findet sich auch in den „Zapiski molodogo čeloveka“ ein auffälliges „Durcheinander von Fakten, Phänomenen, Episoden, Prospekten, Bewusstseinsdaten (...), die nur durch Assoziation, Reflexion, Gedächtnis des niemals gänzlich fiktiven Autors miteinander in Kontakt kommen." ${ }^{\circ}$

Vor allem die auffällige Durchbrechung der literarischen Fiktion durch ein vornehmlich autobiographisch fundiertes Schreiben und die auf den ersten Blick eher zufällig wirkende Kombination der unterschiedlichsten Fakten, Assoziationen und Reflexionen bestimmen die Komposition und die Stilistik dieses ersten, von Herzen publizierten literarischen Textes, den „Zapiski molodogo čeloveka“, mit denen er seine vorausgehenden romantischmelodramatischen Erzählungen „Elena“" und „Legenda“" weit hinter sich lässt. ${ }^{9}$ Dabei werden nur im ersten Teil, aus der Ich-Perspektive, die sehr persönlichen Erfahrungen der Kindheit und Jugend unter der Beobachtung des strengen und unnahbaren Vaters geschil-

1954, S. 258. Alle folgenden Zitate aus Herzens literarischen Werken und publizistischen Schriften beziehen sich auf diese bislang vollständigste Ausgabe.

HEINE, ebd.

PREISENDANZ, S. 30.

Die beiden von Herzen auch später nicht publizierten Erzählungen sind jetzt leicht zugänglich in: GERCEN, Bd.1, M. 1954, S. 81-106 und S. 139-169. Einen ausführlichen Kommentar zu diesen beiden, den „Zapiski molodogo čeloveka“ vorausgehenden, Texten bietet I. NovIC, Molodoj Gercen, M. 1980, S.167-225. Eine stärker auf die Poetik und den sich verändernden Wirklichkeitsbezug der Texte bezogene Darstellung bietet demgegenüber die konzise Studie von M. PARTRIDGE, Herzen's Changing Concept of Reality and its Reflection in his Literary Works, in: The Slavonic and East European Review, vol. XLVI, nr. 107 (July 1968), S. 397-421. 
dert, während die liebevolle deutsche Mutter, anders als später in den Memoiren, noch kaum erwähnt wird. Demgegenüber wird im zweiten Teil, mit dem Hinweis auf ein zufällig aufgefundenes Manuskript, aus der distanzierteren Perspektive der Er-Erzählung in erster Linie das eintönige und bedrückende Leben in der fiktiven Stadt Malinov in komisch-satirischer Form geschildert, während hier die persönlichen Erlebnisse und Erfahrungen des ,jungen Mannes“ eine sehr viel geringere Rolle spielen. Allerdings fällt auf, dass bereits das Porträt des ,jungen Mannes“ nicht ausschließlich Herzens eigene Kindheits- und Jugenderfahrungen zusammenfasst, sondern gleichzeitig auf Griboedovs „Gore ot uma“, Puškins „Evgenij Onegin“, Lermontovs „Geroj našego vremeni“ und die persönlichen Schilderungen der Hauslehrer und Bediensteten über die Französische Revolution und den gescheiterten Dekabristenaufstand verweist, um auf diese Weise gleichzeitig den literarisch-kulturellen und politischen Kontext der Erlebnisse und Erfahrungen des Ich-Erzählers in Erinnerung zu rufen. Neben Goethe, Schiller und Byron waren es vor allem diese literarischen Texte und die mündlichen Schilderungen der Erzieher, die dem ,jungen Mann“ das einsame, isolierte Leben im Hause seines reichen, aber despotischen Vaters erleichtert oder allererst erträglich gemacht haben sollen. Dabei waren es vor allem Schillers Dramen und Žukovskijs philosophische Lyrik, die die idealistischen Überzeugungen und Zukunftvisionen des Verfassers der „Aufzeichnungen“ so nachhaltig geprägt haben, dass er deren Wirkung auf das eigene Weltverständnis in folgender Weise zusammenfasst:

Душа, однажды предавшаяся универсальной жизни, высоким интересам, и в практическом мире будет выше толпы, симпатичнее к изящному; она не забудет моря и его пространства $(\ldots)^{10}$

Bedauerlicherweise sind die ursprünglich ebenfalls bereits für die „Zapiski“ vorgesehenen Erinnerungen an das anregende und glückliche Studentenleben in Moskau nicht in den seinerzeit publizierten Text übernommen worden und deshalb nur zum Teil erhalten geblieben. Aber das ursprünglich ebenfalls für die „Zapiski“ vorgesehene Fragment „O sebe“, in dem die intensiven Debatten zwischen Herzen und seinen Freunden geschildert werden, vermittelt einen Eindruck davon, wie sehr die Philosophie des deutschen Idealismus und die Literatur der Romantik in den frühen Jahren auch das eigene Schreiben und Empfinden geprägt haben. So beschreibt Herzen seine enge Freundschaft mit Ogarev und die gemeinsame Begeisterung bei der Betrachtung eines Sonnenaufgangs in Moskau in der folgenden stark lyrisierten Passage, mit der er das frühere Naturerlebnis möglichst direkt und unverfälscht zum Ausdruck zu bringen versucht:

Они стояли молча, - о чем тут было говорить, и не думали, и не молились - a высоко было сочувствие их в ту минуту с творцом, с природою, с человечеством. (...) Месяц мечтаний, односторонней жизни закатывался, солнце жизни выступало с своею огненною, всепоглощающею любовью, (...). ${ }^{11}$

Die intensive Erfahrung der Entfremdung des jungen Adligen im Haus seines unnahbaren, stark depressiven Vaters scheint zumindest kurzzeitig aufgehoben zu sein, indem das gemeinsame Naturerlebens das Ideal eines harmonischen Lebens präfiguriert, während der

10 GERCEN, Bd. 1, S. 276.

11 Ebd., S. 181f. 
später so oft zitierte Schwur auf den Sperlingsbergen in den frühen „Zapiski“ noch nicht erwähnt wird. Erst in den späteren Memoiren wird Herzen berichten, dass er sich schon in seiner frühesten Jugend, zusammen mit seinem Freund Ogarev, dazu verpflichtet habe, die autokratische Herrschaft Nikolajs I. mit allen ihnen zur Verfügung stehenden Mitteln zu bekämpfen. Ähnlich wie in der späteren Autobiographie, aber noch ungleich persönlicher und emphatischer wird in dem Fragment „O sebe“ stattdessen das glückliche gemeinsame Leben der jungen Adelssöhne an der Moskauer Universität beschrieben. Herzen stilisiert sich schon in diesem frühen Text zu einem gleichzeitig von der Literatur und Philosophie und den exakten Naturwissenschaften geprägten kritischen Intellektuellen, dessen uneheliche Geburt und dessen distanziertes Verhältnis zu seinem Vater ihn die Diskrepanz zwischen den hohen idealistischen Erwartungen während des Studiums an der Moskauer Universität und dem eintönigen Leben in seinem Elternhaus besonders stark erleben lässt. Die intensive Beschäftigung mit der Philosophie des deutschen Idealismus und der Literatur der europäischen Romantik ändern indessen nichts daran, dass sich bereits der junge Herzen als ein unglücklicher Außenseiter, als ein „lišnyj čelovek“ empfindet, der seine adlige Abstammung, seine aristokratischen Lebensformen und seinen ungewöhnlichen Reichtum nur schwer mit den utopischen Zielen Saint-Simons und den noch weiter reichenden revolutionären Zielen der übrigen frühen französischen Sozialisten zu vereinbaren vermag.

Dem romantischen Idealismus und der mit ihm verbundenen Hoffnung auf eine grundlegende Veränderung der bestehenden Welt wird im zweiten Teil der „Zapiski molodogo čeloveka" das geistlose, ausschließlich auf gesellschaftliches Prestige, persönliche Bereicherung und die Rangtabelle der zaristischen Beamten ausgerichtete Leben in der russischen Provinz gegenübergestellt. Dass dabei Vjatka, wohin Herzen selbst verbannt worden war, nicht direkt benannt und geschildert wird, erklärt sich zunächst zweifellos mit der Rücksicht auf die strengen Zensurbestimmungen. Versichert doch der Herausgeber des angeblich ganz zufällig an ihn gelangten Manuskripts in einer ironischen Anmerkung ausdrücklich, dass es sich bei dieser Schilderung um eine reine Fiktion handele, da die beschriebene Provinzstadt nirgendwo auf der Welt existiert habe. Dieser Hinweis trägt aber gleichzeitig und vor allem dazu bei, dass sich die von Beamten und Kleinbürgern bevölkerte Stadt, wie der ebenso anonyme Ort in Gogol's „Revizor“, als ein stark verfremdeter und hyperbolisierter „sbornyj gorod“ lesen und beurteilen lässt, der auf die Lebensformen und Lebensgewohnheiten im zaristischen Russland im ganzen verweist. ${ }^{12}$ Wie in Gogol's Komödie wird auch von Herzen in diesem Abschnitt ein komisch-groteskes Porträt einer in Routine und Langeweile gleichsam erstarrten Provinzstadt entworfen, deren Bewohner die Sinnlosigkeit und Entfremdung ihres Lebens nicht einmal mehr selbst wahrzunehmen scheinen. Da Herzen, anders als später in seinen Memoiren, ausdrücklich nicht beschreibt, wie auch der Verfasser der „Aufzeichnungen“ als Staatsbeamter selbst zu einem Teil dieser von Standesdünkel, Neid und Korruption beherrschten beschränkten Welt hätte werden können, gewinnt die Darstellung zugleich an satirischer Schärfe und an komischer Wirkung, wenn es etwa über den Ball im Hause des Polizeimeisters ironisch heißt:

12 Vgl. dazu die entsprechenden, Realitätsdarstellung und Phantastik miteinander verknüpfenden Überlegungen über den „sbornyj gorod“ bei JU. MANN, Komėdija Gogolja „Revizor“, M. 1966, S. 1032. 
В двенадцать часов губернатор окончил бостон, вычодит в залу и танцует кадриль с хозяикой дома. В Манилове все танцуют - от грудныч детей до столетных старцев - так, как все играют в бостон. Можно думать, что все жители заражены пляской Витта. Потом треск, шум, sensation. ${ }^{13}$

Die so stark an Gogol`s komisch-ironischer Darstellungstechnik orientierte Schilderung der Provinzstadt mit ihren ermüdenden Ritualen und ihrer umfassenden Autoritätsgläubigkeit fällt umso mehr ins Gewicht, als sich Herzen in einer weiteren ironischen Anmerkung auf die seiner eigenen Schilderung vorausgehende Beschreibung des fiktiven Städtchens Malinov in V.I. Dal's Erzählung „Bedovik“ bezieht, die nur ein Jahr zuvor ebenfalls in den „Otečestvennye zapiski“ erschienen war. Während sich Dal’ in der Tradition der frühen ,natural'naja skola“ noch darauf beschränkt, das freudlose Leben des kleinen Beamten Evgenij Lirov in allen Einzelheiten zu schildern, konzentriert sich Herzen schon in seinen frühen „Zapiski“ darauf, die idealistischen Träume und Erwartungen des ,jungen Mannes" den kleinbürgerlichen Lebens- und Bewusstseinsformen zu konfrontieren, wie er sie selbst während seiner Verbannung in Vjatka kennengelernt und erfahren hatte. Auf diese Weise gelingt es ihm bereits in diesem frühen Text, die späteren, noch sehr viel intensiveren und stärker hyperbolisierten Schilderungen der ,pošlost' pošlogo čeloveka“ aus Gogol's „Mertvye duši“ zumindest ansatzweise vorwegzunehmen, die nur zwei Jahre später veröffentlicht wurden. Allerdings sind in Herzens „Zapiski“ die ironischen und satirischen Schilderungen insgesamt sehr viel realitätsbezogener, weil die Darstellung von Malinov und seiner Bewohner, anders als bei Gogol', nicht so stark in eine groteske bzw. phantastische Dimension verfremdet wird, womit die fiktive Provinzstadt als ein besonders eindrucksvolles und abstoßendes Beispiel der zaristischen Bürokratie und Unterdrückung während der Herrschaft Nikolajs I. lesbar wird. Ähnlich wie in Heines „Reisebildern" ist allerdings die komisch-ironische Brechung der Schilderung auch hier bereits so dominant, dass Malinov und vor allem seine Bewohner am Ende der Erzählung mit einem Sumpf verglichen werden können, in dem jede Bewegung und jeder freie Atemzug schwer fällt.

Herzens frühe „Zapiski molodogo čeloveka“ beschränken sich indessen nicht auf die Darstellung der Kindheit und Jugend eines idealistisch gesinnten jungen Adligen aus einer alten und wohlhabenden aristokratischen Adelsfamilie in Moskau und der ihr kontrastierten komisch-satirischen Schilderung der eintönigen und geistlosen Alltagswelt in der russischen Provinz. In einem letzten Abschnitt wird vielmehr in einem weiteren Kontrast das erfolgreiche, aber eher langweilige Leben des polnisch-russischen Gutsbesitzers Trenzinskij beschrieben, dessen pragmatischer, ausschließlich auf sich selbst bezogener Lebensphilosophie der ,junge Mann“ ebenfalls skeptisch, wenn nicht geradezu ablehnend gegenübersteht. Das eintönige Dasein des Gutsbesitzers ist nach seiner Überzeugung von Einsamkeit, Routine und dem bewussten oder unbewussten Verzicht auf das „Ideal einer höheren harmonischen Existenz “14 bestimmt. Es ist aber eben dieses Ideal eines nicht länger entfremdeten Lebens, dem sich der Protagonist - ähnlich wie der so stark von Rousseau, Schiller und Schelling geprägte Herzen selbst - verpflichtet fühlt, ohne diesen Anspruch auch nur ansatzweise mit der abstoßenden und geistlosen Alltagswelt der russi-

13 GERCEN, Bd. 1, S. 299.

14 Ebd., S. 303. 
schen Provinz in Einklang bringen zu können. Noch wichtiger als dieses distanzierte Porträt eines erfolgreichen und durchaus humanen, aber gleichzeitig egozentrischen Gutsbesitzers, sind jedoch dessen ausführliche Schilderungen von zwei Begegnungen mit Goethe, die Herzen aus zwei früheren eigenen Texten in seine "Zapiski“ übernimmt. ${ }^{15}$ Denn sie zeigen noch einmal die starken Parallelen zu Heines kritischer Auseinandersetzung mit den wichtigsten Repräsentanten der „Kunstperiode“ in Deutschland. Ähnlich wie Heine distanziert sich auch der ,junge Mann“ in den „Zapiski“ von der Weltabgehobenheit und der politischen Indifferenz der Kunst und Literatur, die der Gutsbesitzer Trenzinskij an Goethe und der von ihm vertretenen idealistischen Kunstauffassung so positiv hervorhebt. Aber diese ausdrückliche Wendung gegen die nicht länger zeitgemäße Trennung von literarischer und politischer Praxis hindert ihn nicht daran, gleichzeitig den Dichter Goethe als genialen Künstler zu bewundern, dessen weltliterarische Bedeutung der nur auf seine eigene beschränkte Aufgabe fixierte Gutsbesitzer Trenzinskij nicht hinreichend erkannt und einzuschätzen vermocht habe. Ähnlich wie von Heine wird damit auch von Herzen in seinen frühen "Zapiski“ die tiefe Kluft zwischen der vergangenen Kunst und Literatur der Klassik und Romantik und der Gegenwart mit ihren sehr anderen Interessen und ästhetischen Überzeugungen diagnostiziert und beklagt. Aber gleichzeitig wird die überzeitliche Bedeutung und Wirkung der deutschen Kunst und Literatur von dem ,jungen Mann“, wie von Herzen selbst, in keiner Weise bestritten, auch wenn am Ende der „Zapiski“ vor allem die für die Konstitution und Verbreitung der russischen Romantik so außerordentlich wichtigen Werke von Lord Byron gerühmt und als ein immer noch gültiges Zeugnis der poetischen Einbildungskraft des romantischen Dichters betrachtet werden.

II.

In einer systematischen Studie über die historischen und philosophischen Voraussetzungen der "natural'naja škola“ hat Ju. Mann überzeugend zeigen können, dass sich zumindest die Autoren der bedeutenderen Werke dieser Schule keineswegs darauf beschränkt haben, den nachhaltigen Einfluss des jeweiligen sozialen Milieus auf das Denken und Verhalten der Figuren zum Ausdruck zu bringen. Vielmehr sei es Dostoevskij, Gončarov, Turgenev, aber vor allem auch Herzen gleichzeitig immer auch darauf angekommen, die noch unversehrte Natur des Menschen gegenüber den negativen Einflüssen ihrer gesellschaftlichen Umgebung herauszustellen und auf diese Weise den „dialogischen Konflikt zwischen Pragmatikern und Romantikern“ in den Mittelpunkt ihrer zeitkritischen Prosawerke zu rücken. ${ }^{16}$ Diese Einschätzung trifft zumindest auf die umfangreicheren und psychologisch differenzierteren Texte der „natural'naja škola“ wie Dostoevskijs „Bednye ljudi“, Gončarovs „Obyknovennaja istorija“ oder Herzens Roman „Kto vinovat?“ uneingeschränkt zu, die fast gleichzeitig um die Mitte der 1840er Jahre entstanden und publiziert worden sind. In allen diesen Werken werden die noch der Romantik entstammenden idealistischen Überzeugungen und Lebensentwürfe der Protagonisten

\footnotetext{
15 Vgl. diese beiden, mit den Titeln „Pervaja vstreča“ und „Vtoraja vstreča“ versehenen Texte in: GERCEN, Bd. 1, S. 108-130.

16 Ju. MANN, Filosofija i poetika natural'noj skoly, in: Problemy tipologii russkogo realizma, M. 1969, S. 246.
} 
gleichsam auf den Prüfstand gestellt, um sie der restriktiven Kultur und politischen Realität des zaristischen Russlands nach dem gescheiterten Dekabristenaufstand unter der autokratischen Herrschaft Nikolajs I entgegenzusetzen, von der Herzen als Person und als Schriftsteller durch seine frühe Verhaftung und Verbannung in die russische Provinz besonders direkt betroffen war. Ohne schon die widersprüchlichen psychischen und intellektuellen Voraussetzungen und Verhaltensweisen der Figuren so differenziert zu beschreiben, wie dies später Turgenev, Dostoevskij oder Tolstoj in ihren umfangreicheren Romanen gelungen ist, gehen damit alle diese Texte bereits über eine möglichst eingehende und gleichzeitig dezidiert gesellschaftskritische Deskription der zeitgenössischen Realität weit hinaus, die in den beiden zunächst so besonders stark verbreiteten Kleingattungen: der physiologischen Skizze und der „Erzählung vom kleinen Beamten“" so sehr dominierte. ${ }^{17}$ Zumindest die Autoren der umfangreicheren Erzählungen und Romane waren vielmehr schon früh daran interessiert, immer auch die äußeren und vor allem inneren Widerstände ihrer Heldinnen und Helden gegenüber dem sie umgebenden und ihre individuellen Bedürfnisse einschränkenden Milieu möglichst deutlich zu artikulieren. In allen diesen weniger schematischen Texten der ,natural'naja skola" steht deshalb der meist unlösbare Konflikt zwischen den idealistischen Träumen und Erwartungen der Protagonisten und den egoistisch-kleinbürgerlichen Lebensformen der Beamten, Gutsbesitzer oder Kaufleute im Zentrum, während die Spannungen in den Familien des alten und einflussreichen Adels weitgehend ausgespart bleiben, die Herzen in seinen späteren Memoiren, Turgenev in seinen zeitkritischen Romanen später so ausführlich schildern wird.

Sobald man Herzens einzigen abgeschlossenen Roman „Kto vinovat?“ mit Dostoevskijs „Bednye ljudi“ oder Gončarovs „Obyknovennaja istorija“ vergleicht, die um dieselbe Zeit in Petersburg erschienen, zeigt sich, wie konsequent Herzen auch in der größeren Form des Romans die poetisch-publizistische Schreibweise fortzusetzen und weiterentwickeln $\mathrm{zu}$ versucht, die er - im Anschluss an Heines „Reisebilder“ - in den früheren „Zapiski molodogo čeloveka“" erprobt hatte. Zwar wird das ironische Spiel des Erzählers mit der eigenen Erzählfiktion jetzt stärker zurückgenommen, um die eigene Subjektivität nicht länger mehr so stark hervortreten zu lassen. Jedoch verzichtet Herzen auch im „Kto vinovat?"-Roman sehr bewusst auf eine möglichst distanzierte und ausdifferenzierte Darstellung des Innenlebens seiner Figuren, wie sie Turgenev bald darauf in seinem Drama „Mesjac v derevne“ und seinem nur wenige Jahre später entstandenen „Rudin“-Roman anstrebt und erreicht. Denn ähnlich wie Turgenev in seinen frühen „Zapiski ochotnika“ bemüht sich auch Herzen in seinem um die gleiche Zeit entstandenen Roman um eine möglichst wirklichkeitsbezogene und gleichzeitig dezidiert kritische, gesellschaftsanalytisch ausgerichtete Darstellung von ihm persönlich besonders gut vertrauten Lebensbereichen und Wirklichkeitsausschnitten. Wenn der Erzähler des „Kto vinovat?“-Romans bereits am Ende des ersten Kapitels ausdrücklich hervorhebt, keine längeren Erzählungen oder Romane verfassen zu können, ist dieses Bekenntnis insofern keineswegs nur als selbstkritischer Hinweis auf die eigenen begrenzten schriftstellerischen Möglichkeiten zu lesen und zu bewerten. Soll doch die spätere, durchaus spannende und in sich zusammenhängende

17 Zur Hierarchie der literarischen Gattungen und ihrer zunehmenden Veränderung im literarischen System der „natural'naja škola“ vgl. V.I. KULEŠOV, Natural'naja škola v russkoj literature, M. 1965, insb. S. 114-155. 
Romanhandlung zunächst nur durch „einige biographische Zeugnisse“ vorbereitet und fundiert werden, die der Erzähler ,aus durchaus verlässlichen Quellen geschöpft“ haben will. ${ }^{18}$ In unmittelbarer Übereinstimmung mit Belinskij und dem vor allem von ihm begründeten Programm der ,natural'naja skola“ sollte auf diese Weise die dokumentarische Schreibart und die mit ihr angestrebte möglichst strenge Orientierung der Literatur an der zeitgenössischen gesellschaftlichen Realität betont werden, um diese der vorausgehenden ,romantischen' Erzähltradition gegenüberzustellen, der Herzen in den 1830er Jahren zunächst ebenfalls verpflichtet geblieben war. Wie in den späteren Memoiren werden indessen bereits im „Kto vinovat?“-Roman die Biographien der verschiedenen Romanfiguren und die auf sie bezogenen ausführlichen Milieudarstellungen auf eine kritische Instanz bezogen, von der die bereits durch den Romantitel so stark betonte Schuldfrage wenn auch nicht eindeutig beantwortet, so doch zumindest konsequent reflektiert wird.

Diese, den gesamten Roman gleichsam überformende ,publizistische' Ausrichtung des Romans hat - ästhetisch gesehen - den nicht zu übersehenden Nachteil, dass die verschiedenen Romankapitel vornehmlich durch die Schuldproblematik, nicht aber durch eine überzeugende Interaktion der verschiedenen Romanfiguren miteinander verklammert und aufeinander bezogen werden. Aber wie bereits in den vorausgehenden ,Zapiski molodogo čeloveka" orientiert sich Herzen auch jetzt wieder sehr bewusst an einer poetisch-publizistischen Schreibweise, in der fast zwangsläufig die ästhetische Funktion der Literatur nicht länger im Vordergrund steht, sondern stattdessen ihre operative, aufklärerische Bedeutung und Wirkung dominieren sollte. An die Stelle einer durchgängigen Romanhandlung treten deshalb zunächst einzelne biographische Skizzen bzw. Tagebuchaufzeichnungen der verschiedenen Figuren, die erst im zweiten Teil des Romans durch den tragischen Liebesroman zwischen Vladimir Bel'tov und Ljubov' Kruciferskaja miteinander verknüpft werden. Hinzukommen abstoßende bzw. Mitleid erregende Schilderungen des Lebens auf dem Landgut des Gutsbesitzers und früheren Generals Aleksej Negrov. Er tyrannisiert seine Familie in ähnlicher Weise wie seine leibeigenen Bauern und Bedienstete und führt auf seinem Landgut ein ebenso langweiliges wie sinnentleertes Leben, wie er es zuvor bereits in Moskau vor seiner Verheiratung verbracht hatte. Ebenso ausführlich werden aber, wiederum im Anschluss an Gogol', die Repräsentanten der zaristischen Bürokratie in Petersburg und vor allem die subalternen, aber nicht weniger einflussreichen Beamten in der russischen Provinz geschildert, um die unkontrollierte Macht der Staatsbediensteten und die Willkür der Gutsbesitzer als integralen Bestandteil der autokratischen Herrschaft Nikolajs I. darzustellen und zu entlarven.

Auf diese Weise gelingt es Herzen, durch seine stark fragmentarisierte, von ironischen Kommentaren des Erzählers immer wieder unterbrochene Schreibweise, die unbegrenzte Macht des Zaren und vor allem der zaristischen Bürokratie als eine jede freie Entwicklung des Individuums von vornherein ausschließende und erstickende Atmosphäre darzustellen, womit auch die durch den Titel des Romans so stark in den Vordergrund gerückte Schuldfrage nur scheinbar offen bleibt. In Wahrheit ist es nicht das unkontrollierbare Schicksal oder die mangelnde Überlegenheit und Selbstdisziplin von Bel'tov, durch die die scheinbar so glückliche und idyllische Ehe und Liebe zwischen Ljubov' Kruciferskaja und ihrem rührend um sie besorgten Ehemann zerstört wird. Es ist vielmehr die patriarcha- 
lische, von egoistischen und kleinbürgerlichen Zwängen und Interessen beherrschte Kultur, die in letzter Instanz für die Zerstörung der scheinbar so harmonischen Ehe der Kruciferskijs durch Bel'tov verantwortlich gemacht wird, wenn dessen Verhältnis zu den Provinzbewohnern in folgender Weise beschrieben wird:

Но Бельтов, Бельтов (...), скиталец по Европе, чужой дома и на чужбине, аристократический по изяществу манер и человек XIX века по убеждениям, как его могло принять провинциальное обсцество! Он не мог войти в их интересы, ни они - в его, и они его ненавидели, поняв чувством, что Бельтов - протест, какое-то обличение их жизни, какое-то возражение на весь порядок ее. ${ }^{19}$

Durch die intensive Schilderung der Alltagswelt mit ihren kleinbürgerlichen Normen und Gewohnheiten geht Herzens Schilderung des „lisnyj čelovek“ weit über Puškins „Evgenij Onegin“ oder Lermontovs „Geroj našego vremeni“ hinaus. Die Entfremdung zwischen dem einsamen und unglücklichen jungen Adligen und der ihn umgebenden Welt wird nicht länger diesem selbst oder, im Anschluss an Byron, einer metaphysisch begründeten Instanz zugeschrieben. Sie wird vielmehr jetzt ungleich konkreter mit dessen weltfremder Erziehung und Sozialisation durch einen aus der Schweiz stammenden und an Rousseau orientierten Hauslehrer und dem gleichzeitigen Desinteresse an seinen idealistischen Plänen und Zukunftsvisionen der ihn umgebenden Umgebung begründet. Insofern wird auch sein undiszipliniertes und unmoralisches Verhalten gegenüber Ljubov' Kruciferskaja und ihrem Ehemann, ungeachtet aller persönlichen Schuld, gleichzeitig, wenn nicht sogar vor allem, auf die politischen und kulturellen Verhältnisse zurückgeführt. Sehr viel dezidierter als etwa von Turgenev im „Dnevnik lišnego čeloveka“ oder im späteren „Rudin“-Roman wird von Herzen vor allem die repressive Atmosphäre in der russischen Provinz dafür verantwortlich gemacht, dass der so stark vom deutschen Idealismus und französischen Sozialismus beeinflusste Bel'tov die idyllische, wenn auch ebenfalls bereits zur Routine erstarrte Ehe der Kuciferskijs zerstört, um anschließend nicht länger in Russland, sondern in Westeuropa sein sinnentleertes und perspektiveloses Leben fortzusetzen.

Die kaum zu übersehenden literarischen Schwächen des „Kto vinovat?“-Romans erklären sich nicht allein daraus, dass Herzen, wie bereits in den „Zapiski molodogo čeloveka“, auch in seinem Roman nicht auf pathetische Schilderungen und Kommentare und melodramatische Szenen verzichtet, die nicht recht zu den ironisch-satirischen Beschreibungen der russischen Provinz und der in ihr herrschenden Stagnation und Langeweile passen. Hinzu kommt, dass Herzen in seinem ersten umfangreichen Text auf wenig überzeugende Weise die von Puškin und Lermontov so eindrucksvoll eröffnete Tradition des Romans über den lišnyj čelovek mit der parodistischen Verarbeitung und Umkehrung des klassischen Bildungsromans und des sentimentalen Liebesromans zu verknüpfen versucht. Sollte doch die Darstellung über die Passivität und die verlorenen Illusionen des jungen Adligen Bel'tov, nach dem Vorbild von George Sand, mit der eindringlichen Schilderung von Ljubov' Kruciferskaja kombiniert werden, die dem bestehenden System ebenso fremd und kritisch gegenübersteht wie Bel'tov, sich aber dessen Zwängen und Unterdrückungsmechanismen noch weniger zu entziehen oder zu widersetzen vermag. Auch wenn sie, vor ihrer tragischen Begegnung und Liebesbeziehung mit Bel’tov, explizit mit einem ,jungen

19

Gercen, Bd. 4, S. $122 \mathrm{f}$. 
Tiger, der sich seiner Kraft nicht bewusst ist" verglichen wird ${ }^{20}$, ist sie viel zu sehr auf ihre traditionelle Rolle als Ehefrau und Mutter fixiert, um zusammen mit Bel'tov ihr beschränktes und eintöniges Leben aufzugeben und hinter sich lassen zu können. Auch ihre Beobachtung, dass die Kinder der Leibeigenen des Gutsbesitzers Negrov sehr viel sympathischer und klüger seien als die Nachkommen der wohlhabenden, aber ungebildeten und egozentrischen Adelsgesellschaft, bleibt noch zu beiläufig und zu partiell, als dass sich schon mit ihr Herzens spätere utopischen Hoffnungen auf einen spezifisch russischen Weg zum Sozialismus auf der Basis der obščina, des Gemeineigentums und der bäuerlichen Selbstverwaltung, ankündigten. Ebenso wie die Befreiung der Frau wird auch die Aufhebung der Leibeigenschaft immer wieder thematisiert oder gelegentlich regelrecht verlangt. Aber es sind, wie bereits in den „Zapiski molodogo čeloveka“, die eher abstrakten und idealistischen Träume und Erwartungen von Bel'tov und die ihnen kontrastierten nüchternen, aber nicht weniger humanen Überlegungen des Arztes Dr. Krupov, die der Kulturlosigkeit und der drückenden Atmosphäre des russischen Provinzlebens gegenübergestellt werden. Dabei werden Bel'tovs, an Rousseau und der Philosophie des deutschen Idealismus orientierten Hoffnungen auf eine radikale Veränderung der bestehenden Welt und der in ihr herrschenden menschlichen Beziehungen zwar von Krupov nicht explizit zurückgewiesen. Jedoch werden sie dadurch stark relativiert, dass nicht nur der skeptische Arzt, sondern auch der Erzähler mehrfach auf die unüberbrückbare Kluft zwischen den idealistischen Träumen des jungen Adligen und der Stagnation und Rückständigkeit der Lebensund Bewusstseinsformen in der russischen Provinz hinweist. Zwar sind Krupovs, sehr persönlich motivierte Einwände gegen die nicht länger zeitgemässen ,romantischen' Vorstellungen über die Liebe und Ehe wohl kaum als prinzipielle Kritik an den idealistischen Illusionen von Bel'tov oder an den altruistischen Lebensprinzipen des sympathischen, aber ebenfalls willensschwachen Kruciferskij aufzufassen, der nach den Gerüchten über die Untreue seiner Ehefrau der Trunksucht verfällt. Jedoch zeigt sein solidarisches Verhalten gegenüber Bel'tov und dem mit ihm befreundeten Ehepaar Kruciferskij, dass sein viel bescheideneres Ziel eines humanen, vornehmlich rational begründeten Lebens den unkultivierten, auf gegenseitigem Misstrauen und Neid basierenden Lebensformen der Beamten und Gutsbesitzer nicht weniger deutlich widerspricht. Am Ende des Romans ist Krupov nicht umsonst die einzige Romanfigur, die von der tragischen Liebesaffäre zwischen Bel'tov und Ljubov' Kruciferskaja nicht persönlich betroffen ist und deshalb zugleich als ein väterlicher Freund und als lebenskluger Ratgeber in Erscheinung treten kann. In einem letzten Gespräch mit Bel'tov gibt der im allgemeinen so distanzierte und desillusionierte Skeptiker dem unglücklichen und durch seine egoistische, ungezügelte Liebe schuldig gewordenen Bel'tov den folgenden freundschaftlichen Ratschlag, wobei der Erzähler auch hier wieder nicht auf eine zusätzliche, eher unnötige Kommentierung dieser Abschiedsrede verzichtet:

Владимир Петрович, ну, докажите же, что вы сильный человек; я верю, что вам это трудно, ну, все же принесите жертву, большую жертву... А мы, может, спасем эту женщину; Владимир Петрович, уезжайте отсюда !... 
И какая-то нежность в тоне заменила натянутую жесткость ... голос у старика дрожал. Он любил Бельтова. ${ }^{21}$

Nicht nur der „Kto vinovat?”-Roman selbst, sondern vor allem seine intensive und kontroverse Rezeptionsgeschichte in den 1840er Jahren zeigen, wie direkt Herzen gerade mit diesem so dezidiert gesellschafts- und kulturkritischen Text den Intentionen und der Poetik der „natural'naja škola“ entsprochen hat. So wird von dem konservativen Kritiker in der Zeitschrift „Syn otečestva“ Herzen vorgeworfen, das alltägliche Leben der Provinzbewohner ausschließlich von seiner ,hässlichen, niedrigen und abstoßenden Seite“ geschildert zu haben und sich dabei viel zu direkt an den ähnlich einseitigen Darstellungen in Gogol's „Mertvye duši“ orientiert zu haben. Oder Ševyrev macht Herzen in seiner Rezension im „Moskvitjanin“ den Vorwurf, das Alltagsleben der Beamten, Gutsbesitzer und ihrer Leibeigenen viel zu einseitig an einer abstrakten Idee gemessen zu haben, anstatt es möglichst unvoreingenommen und vollständig $\mathrm{zu}$ beschreiben und zur Kenntnis zu bringen. $^{22}$

Demgegenüber hat Belinskij, der sich persönlich für die Publikation des Romans im „Sovremennik“ eingesetzt hatte, ihn zusammen mit Gončarovs „Obyknovennaja istorija“ als einen besonders gelungenen programmatischen Text der von ihm selbst begründeten ,natural'na škola“ gewürdigt. Dabei hebt er nicht nur Herzens ,,intensive Kenntnis der im Roman dargstellten Wirklichkeit" hervor, sondern rühmt gleichzeitig dessen Fähigkeit, die von ihm dargestellte Realität einer klar erkennbaren Beurteilung zu unterziehen. ${ }^{23}$ Denn noch stärker als Goncarov sei sich Herzen über den Zweck und das Ziel im klaren gewesen, mit dem er seinen Roman verfasst habe. Dadurch sei aber gelegentlich die Poesie nur „als ein Mittel zum Erreichen dieses Ziels eingesetzt worden“ und die den gesamten Roman dominierende „Idee von der Würde des Menschen“ etwas zu deutlich und zu abstrakt zum Ausdruck gebracht worden. ${ }^{24}$ Außerdem wirft Belinskij Herzen, trotz aller Begeisterung über dessen Roman, vor, Vladimir Bel'tov viel zu sehr an Lermontovs Pečorin aus dem „Geroj našego vremeni“ ausgerichtet und ihn deshalb im zweiten Teil seines Romans zu einer geradezu „genialen Natur“ stilisiert zu haben. ${ }^{25}$ Diese Kritik wird der Differenziertheit und der aus ihr resultierenden inneren Zerrissenheit des zentralen Romanhelden allerdings kaum gerecht. Denn es kam Herzen ja gerade darauf an, nach den „Zapiski molodogo čeloveka" noch einmal einen ungewöhnlich begabten jungen Adligen darzustellen, der mit seinen idealistischen Träumen und kulturrevolutionären Ideen an der konservativen und bedrückenden Welt des russischen Provinzlebens scheitert, wie dies Herzen selbst während der Zeit seiner Verbannung in Vjatka und Vladimir erlebt und erfahren hatte.

Der Kritiker Valerij Majkov, der sich um dieselbe Zeit vor allem für die Werke des jungen Dostoevskij einsetzte, hat demgegenüber ebenso wie bereits Belinskij darauf hingewiesen, dass Herzens frühe Prosa sehr viel mehr durch ihre Rationaltät (um) als durch ihren Kunstcharakter (chudožestvennost') überzeugten. ${ }^{26}$ Diese relativierende Beurteilung trifft nicht nur auf die „Zapiski molodogo čeloveka“, sondern auch auf den „Kto vinovat?“-Roman

Ebd., S. 203.

Vgl. diese Rezeptionszeugnisse bei V.A. Putincev, Gercen-pisatel', M. 1963, S. 97f.

V.G. BELINSKIJ, Polnoe sobranie sočinenij, Bd. 10, M. 1956, S. 319.

BELINSKIJ, ebd.

BELINSKIJ, ebd., S. 322.

V. MAJKOV, Kritičeskie opyty (1845-1847), Spb. 1891, S. 280, zitiert nach: PUTINCEV, S. 95. 
durchaus zu. Denn ähnlich wie Heine in den „Reisebildern“ folgt auch Herzen nach seinem Bruch mit der romantischen Erzähltradition einem literarischen und literaturtheoretischen Konzept, bei dem die politisch-publizistische Wirkung der Kunst und Literatur ihrer ästhetischen Funktion ausdrücklich übergeordnet wird. Es ist aber eben diese appellative bzw. operative Dimension der Texte, die Belinskij dazu veranlasste, aus der französischen Tradition den Begriff der Belletristik aufzugreifen und in Russland zu etablieren, um die so stark von Gogol' beeinflusste Literatur der „natural'naja skola“ der Poesie von Puškin und der romantischen Erzähltradition gegenüberzustellen.

\section{III.}

Der für ihn selbst überraschende große Erfolg des „Kto vinovat?“-Romans hat Herzen dazu veranlasst, unter dem Titel „Dolg prežde vsego“ sogleich einen zweiten umfangreicheren literarischen Text in Angriff zu nehmen, den er jedoch niemals zum Abschluss gebracht hat. Seine Emigration nach Westeuropa, der frühe Tod seines Freundes und literarischen Förderers Belinskij, die sich nach der Revolution in Frankreich im Jahre 1848 noch einmal erheblich verschärfenden Zensurbestimmungen, vor allem aber die zunehmende Konzentration auf seine journalistische und publizistische Tätigkeit im Ausland haben dazu geführt, dass Herzen auch später die Arbeit an seinem zweiten Roman nicht wieder aufgenommen hat. Hinzukam, dass der Roman, in dem mit Anatolij Stolygin ein weiteres Mal ein der russischen Wirklichkeit entfremdeter junger Adliger ins Zentrum gerückt wird, keinen entscheidenden Fortschritt gegenüber dem „Kto vinovat?“-Roman darstellte. Die schon in diesem so stark hervortretende politische Tendenz und moralische Bewertung bestimmt diesen zweiten Roman noch stärker, wenn Stolygin sich gegen seine eigenen Überzeugungen auf der Seite der zaristischen Armee an der blutigen Niederschlagung des Aufstands in Polen im Jahre 1830 beteiligt, um sich später in ein katholisches Kloster zurückzuziehen und auf diese Weise seine persönliche Schwäche und Schuld zu bereuen und zu büßen. Eine solche religiöse Auflösung des tragischen Konflikts war mit Herzens aufgeklärtem Denken und dem politischen und literarischen Programm der ,natural'naja škola“ kaum mehr zu vereinbaren und musste deshalb von ihm eher als ein Rückschritt in seiner konsequenten Wendung gegen die romantische Erzähltradition verstanden werden.

Umso gelungener und zeitgemäßer sind zwei kürzere Erzähltexte, die gleichzeitig mit der Arbeit am „Kto vinovat?“-Roman entstanden und ebenfalls im „Sovremennik“ publiziert worden sind. Der erste, mit dem Titel „Soroka-Vorovka“ versehene Text basiert auf einer wahren Begebenheit, die Herzen von dem Schauspieler M.S. Ščepkin berichtet worden war, dem er später seine Erzählung auch widmete. Die konzentrierte Erzählung ist insofern überzeugender als der ungenügend koordinierte Roman, als Herzen in ihr auf den früheren pathetischen Stil und die zu ausführlichen melodramatischen Szenen und Reflexionen weitgehend verzichtet und überdies den publizistischen Kommentar des Erzählers jetzt von der eigentlichen Erzählung deutlicher abtrennt. Dadurch gewinnt der Bericht über einen reichen und kunstbegeisterten Grafen und Gutsbesitzer und dessen skrupelloses Verhalten gegenüber der von ihm abhängigen Schauspielerin an Geschlossenheit und Überzeugungskraft. In der von einem Schauspieler-Kollegen dargebotenen, Authentizität und Wirklichkeitstreue suggerierenden, Geschichte geht es nicht nur um eine nochmalige schonungslose Abrechnung mit dem Leibeigenschaftsproblem und seinen Folgen, die schon im ersten Teil des „Kto vinovat?“-Romans eine so große Rolle gespielt hatte. Durch 
den nüchtern erzählten Bericht des Schauspielers wird vielmehr der persönliche Mut, die moralische Integrität und die Lebensklugheit einer leibeigenen Schauspielerin herausgestellt, die sich den Nachstellungen des Grafen und Gutsbesitzers Skalinskij erfolgreich widersetzt, allerdings daraufhin ihr schauspielerisches Talent nicht länger entfalten kann. Da Herzen einen Schauspieler-Kollegen die tragische Geschichte vortragen und mit eigenen Worten wiedergeben lässt, gelingt ihm eine schlichte, aber gerade dadurch außerordentlich eindrucksvolle und anrührende Erzählung. Sie setzt die romantische Künstlernovelle der 1830er Jahre fort, wobei allerdings Herzen vor allem die politischen und sozialen Konsequenzen der Leibeigenschaft und die diesem in jeder Hinsicht widersprechende außergewöhnliche Begabung einer von ihrem Besitzer schamlos ausgenutzten Schauspielerin in den Mittelpunkt rückt.

Wie die früheren „Zapiski molodogo čeloveka“ ist auch die „Soroka-Vorovka“-Erzählung von einem ausführlichen publizistischen Kommentar begleitet, der über die Entlarvung und Verurteilung der Leibeigenschaft weit hinausreicht. In einer Rahmenerzählung diskutieren ein Vertreter der Slawophilen, ein Westler und ein nicht auf eine dieser Richtungen festgelegter ,junger Mann“, der weitgehend Herzens eigene Auffassungen vertritt, die Schwierigkeiten und Chancen einer Emanzipation der Frau innerhalb der bestehenden russischen Gesellschaft, wobei auch hier wieder auf die zeitkritischen Romane von George Sand Bezug genommen wird. Dabei werden die Vorurteile des Slawophilen wie des Westlers, dass sich unter den patriarchalischen Voraussetzungen der russischen Kultur kaum eine Frau zu einer selbstständigen und selbstbewussten Schauspielerin entwickeln könne, sowohl von dem ,jungen Mann“ als erst recht von dem Schauspieler mit seiner tragisch endenden authentischen Geschichte entkräftet. Versucht doch der Schauspieler den Nachweis zu erbringen, dass bereits jetzt nicht nur in den beiden Hauptstädten, sondern auch in der russischen Provinz sehr wohl ungewöhnlich begabte Schauspielerinnen existierten, die durch ihre individuelle Begabung sogar die engen Grenzen des bestehenden Leibeigenschaftssystems zu überschreiten vermögen, sofern sie nicht durch ihre egoistisch ihre eigenen Wünsche und Interessen verfolgenden Besitzer daran gehindert werden.

Die Erzählung „Soroka-Vorovka“ zeigt noch einmal exemplarisch, wie stark Herzen in seiner intellektuellen Entwicklung nicht nur vom deutschen Idealismus und frühen französischen Sozialismus, sondern auch von der vor allem von George Sand beeinflussten Emanzipationsbewegung bestimmt worden ist. Jedoch deutet sich vor der tiefen Enttäuschung über die gescheiterte französischen Revolution im Jahr 1848 noch kaum Herzens späterer Versuch an, mit dem Verweis auf die obščina, die bäuerliche Gemeinde und kommunale Selbstverwaltung, einen eigenen, den Kapitalismus gleichsam überspringenden Weg zum Sozialismus zu begründen. In der „Soroka-Vorovka“-Erzählung stehen sich vielmehr der skrupellose Graf und die nur ihrer eigenen Moral und Begabung verpflichtete Schauspielerin noch völlig isoliert gegenüber, die in ihrem Widerstand gegen die Annäherungsversuche ihres Besitzers von keinem der übrigen Leibeigenen oder Bediensteten unterstützt wird und deshalb ihren Widerstand schließlich mit dem eigenen Leben bezahlt. Pavel Annenkov, der als eher liberaler Literaturkritiker die sozialkritische Tendenz der Erzählung und ihre publizistische Rahmenhandlung sehr viel kritischer bewertete als Belinskij, hat sie dennoch als einen wichtigen Beitrag zur Entwicklung des frühen Realismus in der russischen Literatur angesehen, wenn er konstatierte: „Mit wie großer Rücksicht auf das ästhetische Empfinden des Lesers ist das Geschehen erzählt, das unter einer anderen 
Feder ihn leicht hätte verletzen und beleidigen können. “27 Dieses Urteil ist insofern zutreffend, als es Herzen tatsächlich gelungen ist, durch den eindringlichen Bericht des Schauspielers seine Kollegin nicht nur als unschuldiges Opfer ihres Besitzers zu schildern, sondern sie zugleich als eine Bewunderung und vor allem Mitleid evozierende junge Frau darzustellen, die durch ihr unerschrockenes Verhalten nicht nur die Vorurteile gegen die Emanzipation der Frau im zaristischen Russland entkräftet, sondern durch ihr ungewöhnliches schauspielerisches Talent und ihre Lebensklugheit den Leser gleichzeitig als individuelle Persönlichkeit zu beeindrucken und zu überzeugen versteht.

Trotz der so deutlich ausgeprägten Kritik an der autokratischen Herrschaft Nikolajs I. und der paternalistischen Kultur des zaristischen Russland steht Herzen vor seiner Emigration nach Westeuropa, ebenso wie Heine in Deutschland, einer radikalen, auch die Herrschaft des Zaren und ihre sozialen und ökonomischen Voraussetzungen betreffenden Revolution eher skeptisch gegenüber. Sowohl für den jungen Adligen Alexander Herzen als auch für den gegen die bestehende Ordnung rebellierenden Bürger Heinrich Heine ist der „Bruch zwischen Geist und Wirklichkeit, zwischen Idee und Alltag, zwischen Tradition und Zukunftserwartungen“ eine konstante Größe ihrer persönlichen Lebenserfahrung und ihres politisch motivierten Denkens und Schreibens. ${ }^{28}$ Die radikale, gelegentlich geradezu missionarisch erscheinende Kritik an der bestehenden Weltordnung vermag diese tiefe Kluft nur zeitweilig zu überdecken, da die weitreichenden Hoffnungen und idealistischen Erwartungen immer wieder von skeptischen Vorbehalten begleitet und relativiert werden, die in der frühen Prosa vorzugsweise von einem Arzt und Naturwissenschaftler vorgetragen werden. Deshalb lässt Herzen sowohl in den ,Zapiski molodogo čeloveka“ als auch im „Kto vinovat?“-Roman unter dem Namen Doktor Krupov einen erfahrenen Arzt auftreten, der die idealistischen Träume und utopischen Hoffnungen des ,jungen Mannes“ beziehungsweise die Illusionen des unglücklichen, von der Welt und sich selbst entfremdeten Adligen Bel'tov immer wieder in Frage stellt und relativiert. Die gleichzeitig mit der Erzählung „Soroka-Vorovka“ enstandene traktathafte, ironisch-sarkastische Erzählung „Doktor Krupov“ geht über diese skeptische Infragestellung dieser weltverändernden Erwartungen und Projektionen noch einmal weit hinaus. In ihr wird durch das Verfahren der ironisch-grotesken Verfremdung die gesamte bestehende Welt als ein Irrenhaus geschildert und denunziert, dessen Bewohner sich selbst über ihren wahren Geisteszustand hinwegtäuschen. Der ursprünglich mit dem Titel „Iz sočinenij doktora Krupova“ versehene, eine wissenschaftliche Abhandlung parodierende Text schildert zwar noch einmal das abstoßende geistlose Provinzleben und knüpft insofern direkt an die entsprechenden komisch-ironischen Passagen der frühen „Zapiski“ und des „Kto vinovat?“-Romans an. Jedoch wird dieser, wiederum stark an Gogol' orientierter, Schilderung des Provinzlebens nicht länger ein idealistisch und revolutionär gesinnter junger Adliger konfrontiert. Stattdessen steht dieser beengenden, von religiösen, familiären und gesellschaftlichen Vorurteilen beherrschten Welt der geistig behinderte Sohn eines Küsters gegenüber, der nur zu der ihn umgebenden Natur, seinem Hund und dem Ich-Erzähler eine intensive freundschaftliche Beziehung unterhält, während ihm die ihn umgebende Welt der Menschen,

\footnotetext{
27 Vgl. Annenkovs „Zametki o russkoj literature prošlogo goda“ auszugsweise im Hinblick auf Herzen in: GERCEN, Bd. 4, S. 330.

28 W. Preisendanz, Heinrich Heines Dichtertum, in: ders., Heinrich Heine. Werkstrukturen und Epochenbezüge, S. 12.
} 
einschließlich seiner eigenen Eltern, fremd, wenn nicht geradezu feindlich gegenübersteht. Durch die pointierte Kontrastierung der unverfälschten Welt der Natur im Sinne Rousseaus und Schellings und der von Neid und gegenseitigem Misstrauen geprägten Welt der menschlichen Zivilisation geht Herzens Erzählung über eine satirische Darstellung der russischen Provinz und des restriktiven gesellschaftlichen Systems unter der Herrschaft Nikolajs I. weit hinaus. Wie vor ihm bereits Gogol' in den „Mertvye duši““ bietet auch Herzen vielmehr eine komisch-grotesk übersteigerte, wenn auch sehr viel stärker politisch ausgerichtete Darstellung einer ,verkehrten Welt“, in der das Schicksal und die Geschichte der Menschheit als ein von patriarchalischen Familientraditionen, gesellschaftlichen Konventionen und religiösen Vorurteilen beherrschtes Martyrium geschildert werden. Dabei erweisen sich eben die, die die vermeintlich Geistesgestörten verfolgen und in einem Irrenhaus wegsperren, als die eigentlich Wahnsinnigen, da sie wegen ihrer Anpassung an die Normen und Zwänge der bestehenden Gesellschaft ihre wahren menschlichen Fähigkeiten und Bedürfnisse kaum mehr erkennen und zur Geltung bringen. An ganz unterschiedlichen Paradigmen aus der Antike, dem Mittelalter und der Geschichte des 19. Jahrhunderts versucht deshalb der Arzt Dr. Krupov seine Überzeugung zu demonstrieren und $\mathrm{zu}$ begründen, dass die Menschheit bis in die Gegenwart hinein noch niemals ihre wahre Bestimmung habe erreichen können, weil sie an ihre eigenen klein- und spießbürgerlichen Vorurteile und Gewohnheiten gebunden geblieben sei. Dabei verzichtet Herzen, vermutlich mit Rücksicht auf die Zensur, ausdrücklich darauf, diesen Irrweg der Menschheit auch historisch und gesellschaftlich zu begründen. ${ }^{29}$ Stattdessen beschränkt sich der Arzt darauf, die seit Jahrhunderten bestehenden Kulturtraditionen zu benennen, die die Menschen, auch unabhängig von ihrer sozialen Stellung und ihren persönlichen Familienund Besitzverhältnissen immer wieder daran hindern, ihre Entfremdung von sich selbst und der sie umgebenden Welt zu durchschauen und $\mathrm{zu}$ überwinden. Deshalb kommt der Skeptiker und Aufklärer Krupov zu dem sich aus seinen langjährigen empirischen Beobachtungen und wissenschaftlichen Experimenten ergebenden Feststellung, das die Insassen des von ihm geleiteten Irrenhauses in Wirklichkeit ,selbständiger, unabhängiger, origineller, möglicherweise genialer" seien als die einfältigen, in Freiheit lebenden Bewohner der Provinzstadt, die die sie umgebenden, in der ironisch-sarkastischen Darstellung des Arztes geradezu absurd anmutenden Lebensverhältnisse weder durchschauen noch auch nur ansatzweise in Frage zu stellen vermögen. ${ }^{30}$

Belinskij hat die komisch-grotesken Aufzeichnungen und Tagebuchaufzeichnungen des Arztes und Psychiaters Dr. Krupov als Herzens gelungenstes literarisches Werk betrachtet. Denn die sarkastische Ironie, mit der Krupov nicht nur das zeitgenössische Russland, sondern die fatale Geschichte der Menschheit im ganzen geschildert habe, habe seiner spezifischen intellektuellen und literarischen Begabung in besonderer Weise entsprochen. Überdies habe er durch die intensive und einfühlsame Schilderung des Küstersohns Levka eben die Humanität zum Ausdruck gebracht, die der Erzählung zusammen mit der vorherrschenden satirischen Ironie gleichzeitig eine ausgeprägte poetische Dimension verleihe.

29 Die Abschnitte „Otnošenija graždanskie i obščestvennye; otnošenija k cerkvi i gosudarstvu“ aus den komisch-ironischen Aufzeichnungen des Arztes werden zwar ausdrücklich als Überschriften der Abhandlung zitiert, aber bezeichnenderweise nicht näher ausgeführt, sondern durch anschauliche Beispiele aus der Praxis ersetzt (vgl. GERCEN, Bd. 4, S. 256). 
Damit entsprach die traktatartige Erzählung „Doktor Krupov“ aber in besonderer Weise Belinskijs Erwartungen an eine zeitgemäße gesellschaftsanalytische Literatur, wie er sie unter der Bezeichnung ,natural'naja škola“ seit der Mitte der 1840er Jahre durchzusetzen und auch literaturtheoretisch zu begründen versucht hatte. Die intensive Darstellung der „pošlost' poslogo čeloveka“, die bereits Puškin an Gogol's Prosa gerühmt hatte, wird von Herzen in der Weise konkretisiert und ,realistisch' motiviert, dass sie sich sehr viel direkter als die ihr vorausgehenden komisch-grotesken Schilderungen von Gogol' auf das zeitgenössische Russland unter der Herrschaft Nikolajs I. beziehen ließen. Gleichzeitig erschöpfte sich aber gerade die Erzählung „Doktor Krupov“ nicht in der möglichst wirklichkeitsgetreuen Darstellung und kritischen Gesellschaftsanalyse. Die komisch-satirische Darstellung des Irrenhauses und der russischen Provinz wird durch die intensive, die Sympathie des Lesers erweckende Schilderung des Küstersohns Levka ergänzt, womit zumindest ansatzweise auch die Perspektive eines anderen, mit der Natur in Einklang befindlichen Lebens entwickelt wird. Insofern war Herzen insbesondere in der „Doktor Krupov“Erzählung eben die Synthese von Poesie und Publizistik gelungen, die bereits Heines „Reisebilder“ auszeichnet und die Herzen in seiner frühen Prosa ebenfalls anstrebte.

Zwanzig Jahre später hat Herzen seine Erzählung durch sie ergänzende und gleichzeitig modifizierende komisch-ironische „Aphorismata“ ergänzt, die er einem fiktiven früheren Kollegen von Krupov, dem Adjunkt-Professor Tit Levafanskij, zuschreibt. Auch wenn Levafanskij Krupovs skeptische Auffassungen über den wahren Zustand der Menschheit und der menschlichen Gesellschaft weitgehend teilt und bestätigt, werden von ihm dessen Beobachtungen über den Wahnsinn in entscheidender Weise modifiziert und relativiert. Zumindest der Wahnsinn einzelner, besonders begabter Individuen wird von ihm mit der schöpferischen Mania der griechischen Philosophie in Verbindung gebracht und auf diese Weise von dem Irrsinn und dem falschen Bewusstsein der Masse kategorial unterschieden. Die Geschichte der Menschheit, vor allem aber die Geschichte der Kunst und Literatur ist deshalb für den Verfasser der „Aphorismata“ eine vor allem von Zufällen und nicht zu prognostizierenden Ausnahmeerscheinungen bestimmte Entwicklung. Deshalb fasst er seine Beobachtungen in der folgenden Feststellung zusammen, mit denen er über die früheren rationalen Argumente und skeptischen Reflexionen seines Kollegen Dr.Krupov weit hinausgeht:

Не в уме сила и слава истории, да и не в счастье, как поет старинная песня, а 8 безумии. (...) Умом и словом человек отличается от всех животных. И так, как безумие есть творчество ума, так вымысел - творчество слова. ${ }^{31}$

Diese prononcierte Feststellung ist für ein angemessenes Verständnis schon der frühen Prosa außerordentlich aufschlussreich. Trotz aller literarischen Schwächen stellt sie den Versuch eines jungen Adligen und Intellektuellen dar, im Medium der Literatur, unter den Bedingungen einer restriktiven Zensur, seine weit reichenden revolutionären Erwartungen und Perspektiven mit seinen liberalen, auf die unbegrenzte Freiheit des Individuums und der Kunst ausgerichteten Überzeugungen in Einklang zu bringen. Die früh ausgeprägte Skepsis gegenüber einer teleologischen Geschichtsauffassung im Sinne von Hegel oder Marx und die erst später entwickelte Überzeugung von einem spezifisch russischen Weg 
zum Sozialismus auf der Basis der obščina, des Gemeineigentums und der Selbstverwaltung, verhindern eine konsequente Theorie des politisch-gesellschaftlichen Fortschritts und gleichzeitig eine vornehmlich pragmatisch begründete Literatur- und Kunstauffassung, wie sie später von den Rasnotschinzen Dobroljubov und Černysevskij vertreten wurde. Erst für sie besaß die Literatur nicht länger mehr die Eigenständigkeit und ästhetische Bedeutung, die ihr Herzen und Belinskij, wie Heine in Deutschland, auch noch nach dem „Ende der Kunstperiode“ mit der Konstituierung der „,natural'naja škola“ ausdrücklich zuerkannten. ${ }^{32}$

Während sich Turgenev, Dostoevskij und Gončarov von dem gleichwohl noch sehr engen literarischen und politischen Programm dieser Schule in ihren ausdifferenzierten realistischen Dramen, Erzählungen und Romanen in zunehmendem Maße entfernten, ist ihm Herzen als Publizist, Essayist und als Verfasser seiner Memoiren sehr viel stärker verpflichtet geblieben. Ging es ihm doch auch später immer wieder darum, seine sehr persönlichen Erfahrungen mit der russischen Realität und seine utopisch-idealistischen Hoffnungen in Einklang zu bringen, ohne dabei die skeptischen Einwände und Relativierungen aus dem Blick zu verlieren, die in den frühen Texten von dem Arzt und Naturwissenschaftler Doktor Krupov so nachdrücklich artikuliert werden. Der tiefe Zwiespalt zwischen dem Adligen und dem Revolutionär kommt in der Figur, der Sprache und den skeptischen Reflexionen von Krupov vielleicht am deutlichsten zum Ausdruck, der bereits auf die späteren Arzt-Figuren in Čechovs Dramen und Erzählungen vorausweist. Werden doch schon von Krupov in den frühen ,Zapiski molodogo čeloveka“ die idealistischen Träume des ,jungen Mannes“ von einer grundlegenden Veränderung der Welt erheblich relativiert, um diesen später, in der Form eines ironisch-sarkastischen Traktats, seine pessimistische Theorie über das menschliche Zusammenleben und die tragische Geschichte der Menschheit entgegenzusetzen. Damit weist vor allem die Erzählung „Doktor Krupov“ sehr direkt auf die zwei Jahre später entstandene Essay-Sammlung „S togo berega“ voraus, in der Herzen seine Erfahrungen über die gescheiterte französische Revolution des Jahres 1848 und seine Enttäuschung über die Konsolidierung der bürgerlichen Kunst und Gesellschaft in Westeuropa, wiederum in der Form antithetischer Dialoge, zu schildern und zu reflektieren versucht.

In dem mit dem Titel „Consolatio“ versehenen Essay stehen sich noch einmal eine idealistisch gesinnte junge Frau und ein lebenserfahrener älterer Arzt gegenüber, dem seine Gesprächspartnerin seine ihm selbst nicht bewussten aristokratischen Ansichten und Prinzipien vorhält. Demgegenüber insistiert der nüchterne Arzt darauf, ausschließlich seinen eigenen empirischen Beobachtungen verpflichtet $\mathrm{zu}$ sein, wenn er nur einigen wenigen auserwählten Persönlichkeiten wie Fichte, Schiller oder Byron ihre unbegrenzte Freiheitsliebe attestiert. Dagegen konstatiert der skeptische Arzt bei der großen Masse der Bevölkerung eine durchgehende Bereitschaft zu opportunistischer Anpassung und Unterwerfung, wie sie Herzen selbst während der französischen Revolution im Jahre 1848 und

32 Die grundsätzlichen Differenzen zwischen der Literaturauffassung von Herzen und den ungleich dogmatischeren, die politisch-propagandistische Funktion der Kunst und Literatur verabsolutierenden Überzeugungen von Černyševskij und Dobroljubov lassen sich am direktesten an Herzens 1859 und 1860 im „Kolokol“ erschienenen Artikeln „Very dangerous!“ sowie „Lišnye ljudi i želčevniki“ ablesen. Beide Artikel sind jetzt leicht zugänglich in: GERCEN, Bd. 14, S. 116-121 und S. 317-327. 
zuvor - noch ungleich intensiver - an dem Leben und Verhalten der russischen Kleinbürger und Beamten in der russischen Provinz beobachtet und erlebt hatte.

Auch bei der anschließenden theoretischen und historischen Begründung eines spezifisch russischen Wegs zum Sozialismus hat Herzen den Konflikt zwischen den unverzichtbaren Bedürfnissen einzelner herausragender Persönlichkeiten und den Interessen der in der „obščina“ zu Kollektiven zusammengeschlossenen bäuerlichen Bevölkerung als das zentrale Problem klar erkannt, wenn er in seinem Essay „Panslavisme moscovite et Européisme russe" konstatierte:

L'Europe n'a pas résolu l'antinomie entre l'invidu et l'Etat, mais au moins elle en a posé la question. La Russie s'approche du problème d'un coté opposé, mais elle non plus ne l'a pas résolu. C'est en présence de cette question que commence notre égalité. Nous avons plus d'espérances, car nous ne faisons que commencer, mais une espérance n'est une espérance, que parce qu'elle peut ne pas se réaliser. ${ }^{33}$

Es ist aber eben diese eher unbestimmt bleibende Hoffnung, mit den spezifischen Mitteln der Literatur und Publizistik eine radikale Veränderung der bestehenden politischen und gesellschaftlichen Verhältnisse zu unterstützen, ohne deshalb die geistige Freiheit und materielle Unabhängigkeit des einzelnen Individuums preiszugeben oder auch nur einzuschränken, die bereits Herzens frühe Prosa seit den „Zapiski molodogo čeloveka“ wie ein roter Faden durchzieht. Diese liberale, oft mit einer tiefen Skepsis gegenüber dem politischgesellschaftlichen Fortschritt verknüpfte Einstellung, die Herzen auch gegen jede neue Form der Unterdrückung so entschieden Stellung nehmen ließ, ist ihm von den späteren sog. Nihilisten und den politischen Anführern der Narodniki-Bewegung immer wieder zum Vorwurf gemacht worden. Denn ihnen kam es darauf an, die vermeintlichen Interessen vor allem der bäuerlichen Bevölkerung über die skeptischen Vorbehalte eines radikal gesinnten russischen Adligen und Intellektuellen zu stellen, dem sie seine adlige Abstammung, seinen persönlichen Besitz und seine daraus resultierenden elitären Standesvorurteile zum Vorwurf machten. Herzen selbst hat demgegenüber, nicht zuletzt unter dem Eindruck der Reformpolitik des neuen Zaren Alexanders II., immer entschiedener darauf bestanden, dass auch noch so progressive Ideen und gerecht erscheinende politische Ziele immer an der konkreten Lebensrealität und den unmittelbaren Interessen und Bedürfnissen der russischen Bevölkerung orientiert und gegebenenfalls von ihnen her korrigiert werden müssten. Und er hat sich deshalb am Ende seines Lebens von den anarchistischen Ideen und radikalen politischen Forderungen seines Jugendfreunds Michail Bakunin nachdrücklich distanziert, dessen revolutionäre Energie und Konsequenz er noch 1851 in einem umfangreichen literarischen Porträt so vorbehaltlos gerühmt und anerkannt hatte. ${ }^{34}$

Jochen-Ulrich Peters, Universität Zürich, Slavisches Seminar, Plattenstrasse 43, CH-8032 Zürich(jupeters@slav.uzh.ch)

GERCEN, Bd. 7, S. 112.

Vgl. den ursprünglich für den französischen Historiker J. Michelet verfassten Essay „Michel Bakounine" in: GERCEN, Bd. 7, S. 340-350. Die entschiedene Distanzierung von Bakunin und dessen ungebrochene Hoffnung auf eine umfassende revolutionäre Erhebung in Russland in den 1860er Jahren, die Herzen für ebenso illusorisch wie gefährlich hielt, manifestiert sich insb. in seinen „Pis'ma staromu tovarišču“ in: GERCEN, Bd. 20, S. 588-591. 